but regions of greatest possible number of collisions associated with greatest luminosity.

It would be a comfort if the comet, to partly untie a hard knot for us, would divide itself as Biela's did. Then, I think, the whirl idea would be considerably strengthened. I could not help contemplating the possibility of this when the meaning of the "ears" first forced itself upon my attention.

The spectroscopic observations which I attempted, after the telescopic scrutiny, brought into strong relief the littleness of the planet on which we dwell, for a seven hours' rail journey from London had sufficed to bring me to a latitude in which the twilight at midnight was strong enough to show the middle part of the spectrum of the sky, while to the naked eye the tail of the comet was not so long as I saw it in London a week ago.

I had already in observations in my own observatory, with $m y \quad 6 \frac{1}{4}$ in. refractor (an instrument smaller than one of Mr. Newall's four finders!) obtained indications that the blue rays were singularly deficient in the continuous spectrum of the nucleus of the comet, and in a communication to NATURE I had suggested that this fact would appear to indicate a low temperature.

This conclusion has been strengthened by Sunday night's observations, and it was the chief point to which I directed iny attention. The reasoning on which such a conclusion is based is very simple. If a poker be heated, the hotter it gets the more do the more refrangible-i.e. the blue-rays make their appearance if its spectrum be examined. The red colour of a merely red-hot poker and the yellow colour of a candle-flame are due, the former to an entire, the latter to a partial, absence of the blue rays. The colour, both of the nucleus and of the head of the comet, as observed in the telescope, was a distinct orange yellow, and this, of course, lends confirmation to the view expressed above.

The fan also gave a continuous spectrum but little inferior in brilliancy to that of the nucleus itself; while over these, and even the dark space behind the nucleus, were to be seen the spectrum of bands which indicates the presence of a rare vapour of some kind, while the continuous spectrum of the nucleus and fan, less precise in its indications, may be referred either to the presence of denser vapour, or even of solid particles.

I found that the mixture of continuous band spectrum in different parts was very unequal, and further that the continuous spectrum changed its character and position. Over some regions it was limited almost to the region between the less refrangible bands.

It is more than possible, I think, that the cometary spectrum, therefore, is not so simple as it has been supposed to be, and that the evidence in favour of mixed vapours is not to be neglected. This, fortunately, is a question on which I think much light can be thrown by laboratory experiments.

J. NORMAN LOCKYER

P.S.-n(By Telegraph.)-Wednesclay, night.-Sunday's observations are confirmed. The cometary nucleus is now throwing off an ear-like fan. Ten minutes' exposure of a photographic plate gave no impression of the comet, while two minutes' gave results for the faintest of seven stars in the Great Bear.

\section{THE FORMS OF COMETS*}

\section{I.}

A FEW years ago astronomers studied comets almost solely to determine their movements. So little advance had been made in the study of the figures of these bodies, that M. Arago believed himself justified in stating in his "Astronomie populaire :"-_ "I

* A lecture by M. Faye delivered at the "Soirées Scientifiques de la Sorhonne." Transiated from La Revme Scientifigue. don't know' will still be the reply we have to make to questions asked concerning the tails of comets." If I venture to take as the principal subject of this lecture the researches which I have undertaken during recent years in this difficult subject, I hope to disarm criticism beforehand by at once declaring that the results contrast singularly, by their imperfection, with the degree of power and of certainty we admire in the other more ancient branches of astronomy.

The reason of this contrast is very simple. While planetary astronomy received the precious heritage of the science of the Greeks and the treasury of observations bequeathed by the highest antiquity, cometary astronomy finds in the archives of history observations travestied by superstitious terror. One of the strongest prejudices of previous centuries was that which attributed to the stars a mysterious influence on our destinies. And comets, by their unforeseen appearance in the midst of the familiar constellations, their monstrous heads, their gigantic tails, were calculated to inspire a sort of apprehension which judicial astrology, that long infirmity of the human mind, did not fail to interpret as menacing presages; and as catastrophes have not been wanting in every period of our history, the singular sophism, post hoc, ergo propter hoc, so natural to our poor logic, helped to confirm ten or twelve times in a century this miserable superstition.

Did a comet appear in the heavens, morning or evening, the astrologer had to be consulted. He did not go to work without rules; he had a complete classification of strange forms under which these heavenly bodies already had been observed, and to each form was attached a particular signification. Pliny has preserved this nomenclature for us: Hevelius, the learned pensionnaire of Louis XIV., faithfully reproduced it in the middle of the 17 th century, in the fantastic figures of his Cometographic. And, certainly, everything was taken in the most literal manner: in a comet with a crooked, or straight, or multiple tail they traced, such is the power of imagination, a gigantic sabre, a lance, or a fiery bolt, a burning torch or a dragon hurling upon an entire country the plague, rebellion or famine. Figs. $I$ and 2 are indications of this idea taken from the "Theatricum cometicum" of Lubienitzki. The first comet, in the form of a blazing torch, indicates very clearly by the direction of its tail the flames which will consume the neighbouring town; the second, a veritable dragon, whose tortuous folds the artist has reproduced, threatens France and Ireland from the seven points of its tongue of fire.

These specimens will suffice; there is no use in producing similar statements and similar pictures; at the most we can barely find here and there in the theories which were then formed some traces of the truth.

Astrology thus stifled real observation until the beginning of the seventeenth century. This may now appear strange to us, but there is no doubt of it. The astronomers of those times, so near in time to ourselves, and already so bold with the universal renaissance of the human mind, were almost all to some extent astrologers. Kepler himself, one of the glorious fathers of modern astronomy, was obliged by the duties of his office as Imperial Astronomer both to draw the horoscope of the war of the Pope against Venice, and to give to his powerful but too-straitened patron, the Emperor Rodolph II., an opinion on the comet of 1607 , which appeared to be menacing Hungary Besides, Rodolph counted much then upon his alchemist to find the gold necessary to pay his army; while his general, the Duke of Friedland, the celebrated Wallenstein, never failed to consult the heavens, always by the help of Kepler, who has preserved for us his horoscope.

But already, from the time of Tycho Brahé, astronomy had commenced to place a hesitating foot in the domain of comets, from which she was soon to drive astrology. Until then men had lived, upon the faith of 
Aristotle, in the thought that comets were not celestial bodies, but mere sublunary meteors; and now it was discovered, by substituting observation for the word of the master, that they journeyed far above the orbits of Mercury and Venus, without being in the least incommoded by the crystalline spheres of the firmament in which the old astronomy incrusted its planets and stars. From the time of Newton comets were at last embraced,

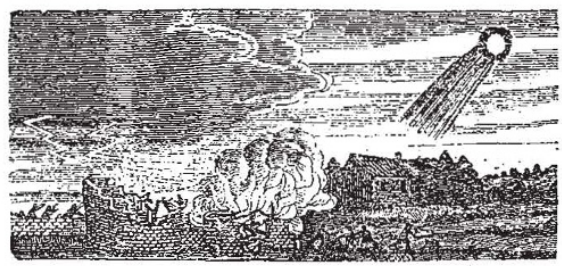

FIG. $x$.

so far as the movement of the nucleus was concerned, in the theory of attraction, and consequently in planetary astronomy, with this single difference, that they described around the sun ellipses enormously elongated, almost parabolic, instead of ellipses almost circular, like the planets. Then astronomers observed carefully the successive positions of these nuclei, and calculated their orbits, but without attending to the figure of the

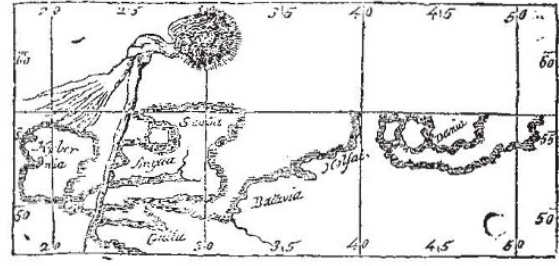

Fig. 2.

comets themselves, although the invention of the telescope must have already revealed a number of curious phenomena which escaped the naked eye. During this period astronomers restricted themselves to representing the comet by a small circle, the centre of which alone was of importance, for there was the centre of gravity to which the laws of Kepler applied, and the calculation of the elements of the orbit. As to the tail, which attracted

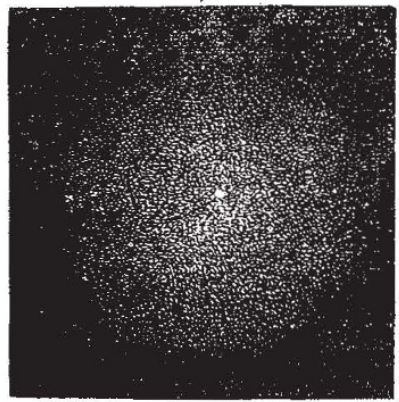

FiG. 3.

no attention, they figured it very simply by some feathery traces attached to the nucleus. In all this there is nothing to attract attention now, any more than the dragons of the astrologers. It was no longer now a superstitious prejudice which took from astronomers the desire to closely examine the facts ; it was a preconceived idea, an elevated idea, no doubt, but too absolute, according to which the only force to be regarded in the celestial spaces was attraction. At bottom it was vaguely felt that the figures of comets were irreconcilable with this ruling hypothesis; and this was sufficient, for the eye was brought to bear by preference upon the subject the most attainable by the reigning theories.

Leaving aside the rude drawings of the six-tailed comet of 1744, by Chézeaux, and those which Messier made by rule and compass, we must come down to the two Herschels before we find trustworthy observations on the form of comets; the beautiful drawings of the comets of $I 8 I I$ and $I 835$ are even now of use to science. Astronomers had at last learned, from the example of Olbers and Bessel, the high importance of these phenomena, which reveal to us more than a new world, since they tell us of a new force in the universe. At present the figure of comets has become the subject of the most earnest research, and the drawings of the beautiful comet of Donati ( 1858 ) which I am about to show you will give you an id.a of the change which, in this respect, has taken place in the minds of astronomers. I can confidently vouch for their fidelity, for, while Bond was executing these drawings at the Cambridge (U.S.) Observatory, by means of a telescope of great power, I followed the same body at Paris with the first telescope which Foucault constructed on his new system, and it appears to me while looking with you on these drawings of Bond, as if I still had that wonderful comet before my eyes.

I shall endeavour first to give an exact idea of the successive metamorphoses which comets present during the course of their appearance, taking as a type a comet which has been perfectly studied-that of Donati. Let us remember that these bodies describe around the sun ellipses extremely elongated, of which the sun occupies the focus; that the point nearest the sun is called the perihtion, while the most distant point (in a truly parabolic orbit this would be infinite) is called the aphelion. Unlike the planets, which describe orbits almost circular, and remain always at nearly the same distance from the sun, comets, in general, come to us from regions much more distant than the most remote planets; but they only become visible, even to the telescope, in the part of their orbit which is nearest to the sun. After their passage at perihelion, their distance from the sun becomes greater and greater, and soon they cease to be visible. I do not believe that any comet has been seen beyond the orbit of Jupiter. It is assuredly not on account of their smallness that they thus escape our notice in regions where the most distant planets, Saturn, Uranus, and Neptune, shine so clearly with the light which they borrow from the sun; this is because the rare and nebulous matter of comets reflect much less light than the solid and compact surface of the planets of which we speak, much less even than the smallest cloud of our atmosphere.

When they are seen far from the sun through a telescope, they appear like rounded nebulosities, but vaguely defined, presenting at the centre a condensation sufficiently marked, which is called the nuclews; it is this nucleus, more brilliant than any other part, whose position astronomers observe. Fig. 3, representing Donati's comet at the time of its discovery, June 5,1858 , gives a sufficient idea of the aspects of all comets when they are at a great distance from the sun.

At a later period, when the comet is approaching its perihelion, it sensibly lengthens out in the direction of the radius vector, i.e. in the direction of an imaginary line which would join the comet and the sun; but then the bright nucleus is no longer found in the centre of the figure, but is situated excentrically on the side nearest to the sun, as is shown in Fig. 4.

Later still, the tail is formed, and is developed more and more, like an opened fan, while the nucleus shines with a more vivid brightness. The comet becomes visible to the naked eye as in Fig. 5 . 
This tail is always away from the sun. At its origin, near the nucleus, it lies in the prolongation of the radius vector; at a greater distance it is curved backwards, as if it met with some resistance which hindered it from following completely the path of the nucleus. The bent axis of this tail is, however, always situated in the plane of the orbit, and this simple fact accounts for the many varieties of aspect presented to our eyes by these cometary appendages. Comets with straight tails appear such only because the eye of the observer is in the plane of the axis of the tail, i.e. in the plane of the orbit. When the earth, in consequence of its annual motion, is carried from this plane, the curvature of the tail becomes manifest; it becomes more and more pronounced as the comet, seen at first edgeways, so to speak, shows itself more and more on the flat, like a scimitar, to the observer.

When the comet, describing the descending branch of its orbit, reaches perihelion, these phenomena acquire their full development. But when it recedes from the sun, describing the ascending branch of its immense parabolic trajectory, the tail diminishes, disappears, and gives place to a mere elongation. Soon it again assumes the spherical form; the nucleus, which has gradually lost its brightness, is indicated only by a slight condensation of light at the centre of a globular mass entirely similar to that which was first seen. Finally this rounded nebulosity disappears.

Upon what scale do these phenomena take place, the immediate cause of which is evidently located in the sun ? What may be the dimensions of these nebulosities, of these brilliant nuclei, of these curved tails? These dimensions are assuredly formidable. The comet of 1843 had a tail of $60,000,000$ leagues, nearly double our distance from the sun. On the sky that tail was drawn like an immense dash of a brush of 65 degrees of angular amplitude. The tail of the famous comet of I8I I was only $40,000,000$ leagues : but, on the other hand, the head alone of the comet $(250,000$ leagues in diameter) was nearly as large as the sun.

As to Donati's comet, its dimensions were more modest its nucleus was $I, 000$ leagues in diameter, and the head only about 13,000 ; the tail was only about $14,000,000$ leagues in length. I had the curiosity to estimate approximately the volume of this small comet, and I found, supposing that the thickness of the tail is equal to its breadth, its volume was a thousand times greater than that of the sun. As in reality the tails are flattened, it will perhaps be necessary to reduce this figure by half. There remains enough to show us that our terrestrial globe, so little beside the sun, is only a point in comparison with these gigantic bodies.

But, on the other hand, everything proves to us that these bodies contain very little matter in so enormous a volume. A character stic which is special to them, and which assuredly belongs neither to the planets nor to their satellites, is their almost absolute transparency. The stars are seen through the tail of a comet as if the tail did not exist ; they can be seen even through the head, much more dense and more brilliant than the tail. It was for long a question whether the nucleus, at least, of a comet would not be opacue and solid like a planet; but, after examination by the most powerful telescopes, it has always been found to be formed of nebulous layers, more and more dense, always permeable by rays of light. This very simple and altogether characteristic fact leads us, by itself, to think that cometary matter must be of extreme rarity, for a mist of some thousands or even of some hundreds of metres in thickness suffices to hide the stars, while a thickness of from 10,000 to 15,000 leagues of cometary matter scarcely lessens their lustre. Desiring to fix our ideas on this subject, I calculated the mass of Donati's comet, and found that it equalled at least that of a sea of Ioo metres in depth, and 16,000 square leagues of superficies. This mass is only a fraction, almost imperceptible, of that of the earth. It was almost entirely concentrated in the head of the comet and around in the nucleus; even supposing it uniformly distributed over the whole volume of the tail, there will be found, for the mean density of that appendage, only a value incomparably more feeble than the density of the void approached by our pneumatic machines. But it is not to this rare gaseous residue that we must compare the matter of comets ; it will resemble

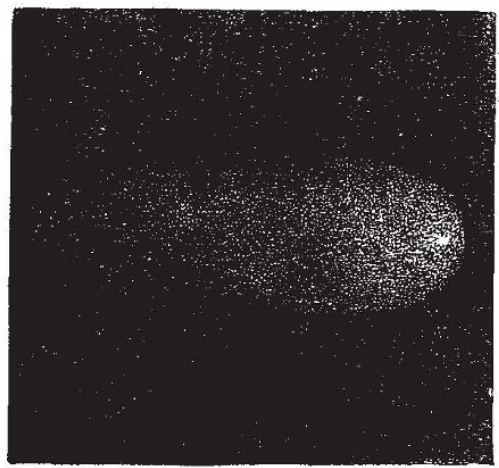

FIG ${ }^{*}$

rather those impalpable grains of dust which dance in the air, and which are disclosed to us by the smallest ray of solar light penetrating a darkened chamber.

Although comets show us matter rarefied to such an extent that a celebrated physicist, M. Babinet, could with considerable justness call them "visible nothings" (riens visibles), do not, however, imagine that their contact with our earth would be without inconvenience. If the nucleus of our comet had directly encountered the earth, with its mass of 25,600 millions of millions of kilogrammes, and its relative speed of seventeen leagues per second (seven for the earth and ten in an opposite direction, for this retrograde comet), the actual ener sy of the shock would be enormous; I calculated that its transformation into heat would immediately generate fifty-ore million calories per square metre of the hemisphere which sustained the shock. It would beenough to shatter, dissolve,

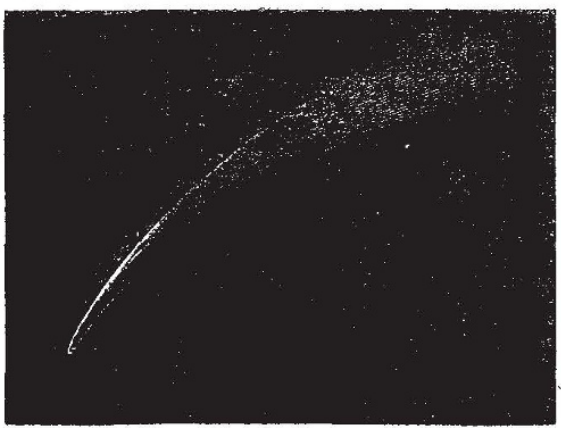

FIG. 5.

and volatilise a part of the solid crust of our globe. No living being could survive such a catastrophe. Happily the probability of such an encounter is excessively small; and, indeed, the most remote geological ages do not bear any traces of such an adventure. We cannot, however, forget that meteors and shooting stars, perhaps even the aerolites which bombard us so regularly every year and every day of the year, have probably the same origin as comets, and result from a mass of analogous materials which are decomposed in penetrating our solar world.

(To be continued.) 